\title{
Responsabilidad del Estado en el uso de las redes sociales ${ }^{1}$
}

\section{Responsibility of the State in the use of social networks}

Mario Felipe Daza Pérez²

\section{Resumen}

Conforme con la sociedad digital actual, la interacción activa de los usuarios en plataformas como Facebook, Twitter, Instagram, Zoom, Teams, etcétera, ha hecho que se torne imperioso digitalizar las herramientas que nos gobiernan; concebir ahora las relaciones comunitarias, judiciales, administrativas telemáticamente, con ma-

1 Este trabajo se proyecta como desarrollo a una pregunta problema formulada en conferencia dictada en la Universidad Cooperativa (Sede Ibagué), en mayo de 2020, sobre: "Libertad de expresión en redes sociales: A propósito de los insultos, groserías, fake news, encriptación, anonimato y posición de garantías de los servidores públicos".

2 Abogado asesor y divulgador jurídico, especialista en derecho administrativo y magíster en Derecho Público de la Universidad del Norte, actualmente candidato de la maestría en Derecho del Estado con énfasis y gobierno y desarrollo de las entidades territoriales (falta sustentación de tesis) de la Universidad Externado de Colombia. Para contacto: mario.daza@hotmail.com o en Twitter e Instagram @mariodaza. Co-fundador del Colegio Colombiano de Abogados Administrativistas (CCA), miembro del Colegio de Abogados en Derecho Disciplinario, creador de la Red Iberoamericana de \#DivulgaciónJurídica (REDIJU) y fundador y director ejecutivo del think-tank libertario: "Centro de Pensamiento Libertad y Prosperidad” (CPLP). 
yor razón a partir del fenómeno de la pandemia del coronavirus, ha llevado incluso a que nuestro modo de vida se ajuste a nuevos paradigmas.

Los agentes del Estado constantemente publican, comentan, insultan, bloquean, informan en las plataformas, generando en ciertas ocasiones "daños antijurídicos", materiales o inmateriales, de la cual irresponsablemente a veces con contenidos falsos o malintencionados lesionan los derechos de personas, esto con el fin de generar un interés nocivo en la comunidad. Todos los actos, hechos, acciones, operaciones, omisiones, pueden ocasionar, desde la perspectiva administrativa, una responsabilidad estatal, contractual o extracontractual, derivado del uso de las redes sociales.

Palabras clave: Responsabilidad estatal, daño antijurídico, redes sociales, actividad administrativa, falla de servicio.

\section{Abstract}

According to the current digital society, the active interaction of users on platforms such as Facebook, Twitter, Instagram, Zoom, Teams, etcétera, has made it imperative to digitize the tools that govern us, to now conceive of community, judicial, and administrative relations. Telematically, with greater reason, from the phenomenon of the pandemic coronavirus, which has even led to our way of life adjusting to new paradigms.

State agents constantly publish, comment, insult, block, report ..., thus generating on certain occasions "unlawful damages", whether material or immaterial, which irresponsibly sometimes with false or malicious content infringe the rights of certain people, this in order to generate a new interest in the community. All these acts, facts, actions, operations, omissions, may cause from the administrative perspective a state responsibility either contractual or non-contractual derived from the use of social networks. 
Keywords: State responsibility, unlawful damage, social networks, administrative activity, service failure.

\section{Planteamiento del problema}

Pensarían los lectores que tocar el tema de la "responsabilidad estatal en redes sociales" sería lo mismo que la "sindicación pública" realizada en "medios de comunicación", pero no lo es; si bien existen fallos, así como doctrina acerca de este último punto, se manifiesta diferente su estudio frente al tema específico a considerar.

Es cierto que las plataformas digitales podrían adecuarse como una especie del género referido a los medios de comunicación, pero en canales diferente. Así, el punto segundo hace alusión a la prensa en sí y a su divulgación común, ya sea en noticias televisivas, periódicos, boletines, etcétera, no a las redes sociales, ilustrado en el sentido en que los agentes del Estado causen "daños" por medio de las plataformas digitales mediante comportamientos lesivos, incumpliendo con sus deberes funcionales, en contraposición a los elementos i) materiales, ii) cognoscitivos, y iii) volitivos, relacionados con la función pública.

\section{Introducción}

El artículo 90 constitucional $^{3}$ es la base para la responsabilidad extracontractual estatal en Colombia, es el fundamento que reprocha cuando uno de sus agentes en relación de sus funciones genera un "daño", cuando actúan en su ejercicio, causando así una lesión, lo que indicaría que un reparo patrimonial del perjuicio causado le podría ser imputado a partir de esa acción, ya sea por realizar ciertas conductas encaminadas a informar mal, como pueden ser las deriva-

3 El artículo 90 de la Constitución Política de 1991 expresa: "El Estado responderá patrimonialmente por los daños antijurídicos que le sean imputables, causados por la acción o la omisión de las autoridades públicas. En el evento de ser condenado el Estado a la reparación patrimonial de uno de tales daños, que haya sido consecuencia de la conducta dolosa o gravemente culposa de un agente suyo, aquél deberá repetir contra éste”. 
das de alocuciones, publicaciones, trinos, comentarios, etcétera, en dichas redes sociales ${ }^{4}$.

La sección tercera del Consejo de Estado ${ }^{5}$ ha marcado los derroteros para que se pueda hablar o no en el país de una responsabilidad extracontractual estatal en cualquier sentido (por hecho del legislador, actos terroristas, etcétera), en todo caso, sea cual sea el tema, debe reunir ciertos elementos para que pueda ser reprochado, los cuales han sido fijados por la jurisprudencia, las cuales son las siguientes:

i) Daño o lesión material o inmaterial, y que este sea cierto, determinable o determinado, causado a una o varias personas.

ii) Conducta omisiva, o en nuestro caso activa, imputable a esa autoridad que trina, comenta o publica en cierta red social la noticia dañosa o malintencionada.

iii) Nexo de causalidad entre ambas, que este "daño antijurídico" se cause a raíz de ese comportamiento que tuvo el agente del Estado en relación con su ejercicio de "funciones públicas".

\section{Regímenes de responsabilidad estatal}

Para no adentrarnos de lleno en la tipología que existe actualmente, este artículo abordará las categorías principales de responsabilidad estatal: i) objetivo, y ii) subjetivo, sin entrar a detallar las figuras de atribución que corresponden ya sea a a) el daño especial, b) el riesgo excepcional, etcétera

i) El objetivo, se mira el daño sin la intención o voluntad del sujeto, sin interesarnos si el agente actuó con dolo o la culpa grave o no, por tanto, este no sería el tipo de responsabilidad que se daría en la

4 De la misma forma podría acontecer cuando se deriva de un contrato por el incumplimiento de una de sus obligaciones.

5 Se puede revisar la sentencia del 8 de octubre de 2016 del Consejo de Estado, Exp. 38139, M. P. Andrade Rincón. 
reflexión, porque no se adecúa a sus criterios específicos, ejemplo de ello tenemos: a) la ocupación de inmueble, b) expropiación por motivos de utilidad pública, c) daños al medio ambiente, d) daño especial, e) productos defectuosos, etcétera

ii) El subjetivo, el que nos interesa, en cambio se debe demostrar la culpa grave o el dolo del sujeto agente, con fundamento en el artículo 90 constitucional relacionado con el "daño antijurídico", generado por el comentario o publicación falso o malintencionado en la red social (nexo causal), que en este caso sería porque ha actuado no conforme a derecho, lo cual daría como consecuencia, si se cumple con los presupuestos descritos, una "falla probada del servicio" y no "presunta".

De allí que sea importante saber a qué régimen de responsabilidad debamos adecuarnos en ese tema, porque de ahí se derivan los "títulos de imputación”, que serían mostrados por esa conducta, actividad, hecho, operación o acto ${ }^{6}$ cometido por el sujeto agente, ocasionado por una falla del servicio, por un lado, y por otro, en una lesión de un derecho fundamentalmente protegido (honor, buen nombre, intimidad, etcétera); entonces, dependerá si el perjuicio es material (patrimonial) o extrapatrimonial (inmaterial).

\section{Causas de la responsabilidad estatal en las redes sociales}

Ya hemos dicho que se necesitan tres elementos básicos para que pueda hablarse de una responsabilidad del Estado en Colombia en materia de redes sociales, pero además de esto, se deben analizar características que son necesarias para diagnosticar si se debe reparar

6 Revisar al respecto la sentencia del Consejo de Estado del 24 de enero de 2019, Exp. 46806. M. P. Pazos Guerrero, ya que estableció siguiendo otras providencias cuando procede la reparación directa por la expedición de actos administrativo, esto por una manifestación de la administración en causa de perjuicios al sujeto pasivo. En el mismo sentido, ver la sentencia del 12 de mayo de 2020 del Tribunal Administrativo de Boyacá, rad. 150012331003201100022-00, M. P. Afanador García. 
e indemnizar directamente o no esa "falla del servicio" o "incumplimiento contractual", la cual debe ser probada, a partir de las causas que la originaron.

En sí, se realizaría una imputación no solo subjetiva (dolo o culpa grave), sino también objetiva ${ }^{7}$, en el deber de integrar ese hecho dañoso derivado ya sea de los actos, hechos, actividades, operaciones, acciones, omisiones, etcétera, que causaron esa lesión a determinadas personas (en el caso del contrato serían las obligaciones quebrantadas), independientemente de los criterios de exoneración que se den, ya sea i) hecho de un tercero, ii) culpa exclusiva de la víctima, iii) fuerza mayor o caso fortuito, etcétera ${ }^{8}$.

\section{Elementos adicionales del daño en materia de responsabilidad estatal por redes sociales}

Para el profesor Luis Felipe Botero (2017), siguiendo al tratadista Javier Tamayo Jaramillo, expresa que el “daño” es:

Aquella amenaza, privación o alteración al núcleo de protección (NP) de un sujeto de derecho, individual o colectivo, causado por otro sujeto de derecho, individual o colectivo [que en este caso sería el sujeto agente], de tal intensidad que un sistema de derecho justo no puede aceptar como irrelevante, tenga o no efecto económico mensurable. En consecuencia, no toda lesión (o afectación negativa de su interés) es daño, no todo daño es indemnizable, y

7 Mirar al respecto el trabajo de Rojas-Quiñones, Sergio \& Mojica-Restrepo, Juan Diego, "De la causalidad adecuada a la imputación objetiva en la responsabilidad civil colombiana”, 129 Vniversitas, 187-235 (2014). http://dx.doi.org/10.11144/ Javeriana.VJ129.caio.

8 Hasta ahora se ha hecho un estudio de la teoría de la equivalencia de las condiciones, causa próxima, causa eficiente, causa adecuada, incluyéndose ahora la teoría de la imputación objetiva desarrollada por el derecho civil y penal delictivo, criterios como: i) el riesgo permitido; ii) el principio de confianza; iii) la posición de garante; iv) la acción a propio riesgo; v) la prohibición de regreso, y vi) el fin de protección de la norma, y precisamente este planteamiento se aplica ahora en la responsabilidad evitando los errores por sí solo originados por la teoría causalista. 
no todo daño indemnizable es reparable mediante el pago de una suma de dinero, asimismo, toda amenaza o alteración del NP de un sujeto de derecho es daño cuando se reúnen las condiciones de intensidad y relevancia, y, por tanto, los remedios en sustanciales y procesales han permitido a las víctimas un mecanismo de protección/tutela (p. 102).

Es común que los gobernantes tomen decisiones por las redes sociales, lo cual se pueden tomar éstas como órdenes (escritas u orales), actos, hechos, operaciones, acciones, etcétera; ejemplo de esto han sido las comunicaciones enviadas por el Presidente, Alcalde o Gobernador a los administrados en pleno fenómeno del coronavirus, estableciendo medidas o manifestaciones de poder, exteriorizadas mediante plataforma digital.

Además del criterio del dolo o culpa grave (también, la indemnización por incumplimiento de contrato), el daño ${ }^{9}$ y nexo causal, como hemos dicho, se deben analizar criterios adicionales para poder hablar de una verdadera responsabilidad del Estado ${ }^{10}$, con ocasión del uso de las redes sociales, ya sea por la publicación de noticias falsas o comentarios dañinos, esto, con base en tres elementos que son:

i) Material, que es la divulgación masiva de información "errónea".

ii) Cognoscitivo, que es el conocimiento efectivo de la falsedad de la información que se fabrica o divulga), y

iii) Volitivo, que es la intención de engañar o confundir al público o a una fracción de él mediante el acto, operación, hecho, acción, actividad, etcétera.

9 Por otro lado, Tamayo Jaramillo (2015) define el daño como "todo menoscabo material o moral causado contraviniendo una norma jurídica, que sufre una persona y de la cual haya que responder otra".

10 Para Luis Felipe Botero Aristizábal, en "Nuevas reflexiones sobre el daño", determina que "la amenaza puede ser daño, cuando se advierta con un grado de certeza mayor de la materialización de ese daño puede constituirse”. 


\title{
El daño ocasionado en materia estatal por noticias falsas 0 malintencionadas en comentarios, publicaciones, trinos, etcétera
}

Fernando Pantaleón (1996) afirma que:

\begin{abstract}
Frente a las informaciones objetivamente verídicas (y que no vulneren el derecho a la intimidad) no existe, ni debe existir, remedio jurídico alguno, por dañosas que puedan resultar para la fama de aquel a quien se refieren, y por malévola y execrable que haya sido la intención de quienes las publicaron. En este mismo punto sigue afirmando que juzga también poco sensata la responsabilidad objetiva de los titulares de los medios de información cuando los perjudicados son cargos o servidores públicos; o personajes públicos: por haber participado voluntariamente en controversias o debates públicos, y en esa medida. En dichos supuestos, me inclino, antes bien, por imponer responsabilidad únicamente en los casos de conocimiento de la falsedad de la información o de temerario desprecio hacia la verdad. Yo no lo haría; pero estimo que, para una responsabilidad civil no punitiva, dicha posibilidad cabe en el marco constitucional (p. 296).
\end{abstract}

Según Catalina Botero, el concepto de noticias falsas ${ }^{11}$ o "fake news", aunque no es asunto nuevo, se hizo popular recientemente luego de que Donald Trump comenzará a utilizarlo masiva y recurrentemente para referirse a cualquier problema que no resultara afín a sus intereses políticos o personales. En este sentido, el presidente estadounidense y otros gobernantes han acuñado el término para blindarse de las críticas y, en no pocos casos, para justificar la regulación o la prohibición de ese tipo de información.

En lo que respecta a la "honra" y "honor" debe hacerse una aclaración ya que constituyen dos nociones totalmente distintas, aunque sean consideradas como sinónimos en el universo jurídico, existe una diferencia de uso entre ellos a la hora de no lesionar un derecho constitucionalmente protegido en el marco de la responsabilidad estatal.

11 En Bolivia se aprueba norma que sanciona penalmente a quien desinforme por el tema de coronavirus, ver al respecto el Decreto 4231 de 2020, acto que endurece la sanción con penas de hasta de diez años de prisión. 
El "honor" se refiere a la conciencia del propio valor, independiente de la opinión ajena; en cambio la "honra" o reputación es externa, llega desde afuera, como ponderación o criterio que los demás tienen de uno, con independencia de que realmente se tenga o no honor; uno es el concepto interno -el sentimiento interno del honor-, y otro el concepto objetivo externo que se tiene de nosotros -honra-, tal como lo expresa la sentencia C-063 de 1994 de la Corte Constitucional.

Dice la co-directora de la "Junta de Supervisión de Facebook", siguiendo la sentencia del 25 de enero de 2007, Vereinigung Bildender Künstler v. Austria del Tribunal Europea de Derechos Humanos que:

El elemento volitivo es particularmente útil para distinguir las "fake news". La sátira -aunque no necesariamente-, puede consistir en la publicación de información falsa, a sabiendas de su falsedad, pero sin la intención de engañar o confundir al público ${ }^{12}$. La sátira, de acuerdo con la jurisprudencia del Tribunal Europeo de Derechos Humanos, goza de una protección especial y reforzada de parte del derecho a la libertad de expresión (Vereinigung Bildender Künstler v. Austria del Tribunal Europea de Derechos Humanos, 2007).

12 Aunque ya hemos dicho en otras publicaciones que lo que verdaderamente sujeta al "dolo" o esa "mala intención" es el "conocimiento", y no precisamente la voluntad. Cfr. "En defensa de un dolo puramente cognitivo", de Mario Felipe Daza Pérez, 2020, se expresa que: "De este modo prohíjo lo que expresa Bustos Ramírez, en parte Díaz Pita, Feijoo Sánchez, Anton Oneca y Luis Greco, que el conocimiento es suficiente y necesario (ya que en nada altera el dominio) para saber que un hecho es doloso o no, póngase a pensar en una persona que esté jugando ruleta rusa obligadamente, que un sujeto le impone al otro que tenga que disparar, sólo tiene un cartucho y le da la vuelta a la manzana del revólver y si dispara lo puede matar (ies claro!), habrá voluntad porque si lo hace lo liberara al disparar salga o no la bala, pero mucho antes de la voluntad sabe que si lo hace va a morir (conocimiento)". 
Las acá llamadas "noticias falsas o malintencionadas", según esta misma autora:

Se encuentran, por lo tanto, en principio, amparadas por la presunción general de cobertura del derecho a la libertad de expresión. Es cierto que, en ciertos casos, las denominadas "fake news" pueden llegar a ser constitutivas de alguna de las categorías de discursos no protegidos. Se trata, sin embargo, de casos absolutamente excepcionales en los cuales es necesario que se demuestre que, con independencia de la verdad o falsedad de la información, se trata de uno de los tipos de discurso prohibido. En otras palabras, las "noticias falsas" no constituyen [daño per se] una categoría independiente de discurso no protegido ${ }^{13}$ (Vereinigung Bildender Künstler v. Austria del Tribunal Europea de Derechos Humanos, 2007).

En el reciente Comunicado de Prensa R78/20 ${ }^{14}$ de la Organización de Estados Americanos [OEA] del 18 de abril de 2020, se expresa que:

Los funcionarios públicos [léase agente del Estado] no deberían efectuar, avalar, fomentar ni difundir declaraciones que saben o deberían saber razonablemente que son falsas, que constituyan desinformación, o que muestran un menosprecio manifiesto por la información verificable. En contextos como el actual, en el que se vive una crisis de salud pública, la información oficial debe contar, dentro de lo razonable, con base científica", esto en lo que respecta a las "fake news" concernientes al coronavirus (OEA, 2020).

\section{Ibíd., p. 72.}

14 Cfr. CIDH y RELE expresan preocupación por las restricciones a la libertad de expresión y el acceso a la información en la respuesta de Estados a la pandemia del COVID-19, de la cual expresan: "Sobre el particular, la Resolución adoptada por la CIDH establece que los funcionarios públicos [agentes del Estado] deben observar especial cuidado en sus pronunciamientos y declaraciones respecto de la evolución de la pandemia, y ser conscientes de que están expuestos a un mayor escrutinio y a la crítica pública, aun en períodos especiales. Asimismo, la Comisión recuerda que los funcionarios públicos tienen el deber de asegurarse que con sus pronunciamientos no están lesionando los derechos de quienes contribuyen a la deliberación pública mediante la expresión y difusión de su pensamiento, tales como periodistas, medios de comunicación y organizaciones defensoras de derechos humanos". 
Sobre la base de un análisis que ha hecho el Instituto de Prensa Internacional, la Fundación Bruno Kessler, Pew Research Center, Newsguard, Blackbird, y el Reuters Institute, en conjunto con la Universidad de Oxford y la Alianza Coronavirus Facts (2020), se ha determinado con respecto a la "libertad de expresión en las redes sociales" en lo atinente a las noticias faltas y los comentarios malintencionados del coronavirus, lo siguiente:

Ciento doce millones de posteos, realizados en sesenta y cuatro idiomas, detectaron que un cuarenta por ciento de los mensajes provenían de fuentes poco fiables, falsa o manipulada, el mismo porcentaje para los ciento setenta y ocho millones de tweets fueron producidos por bots, de ciento noventa y un sitios web han publicado referencia incorrecta sobre esta enfermedad, más de ocho millones de correos electrónicos han sido bloqueados por Google, todos ellos circulados en más de setenta países y en más de cuarenta idiomas (párr. 1).

En este punto, García Amado (2011), expresa que:

Cuando se habla de responsabilidad jurídica se hace referencia a la atribución a un sujeto de la responsabilidad por un daño que han padecido una persona (física o jurídica) o un bien jurídico. Por bien jurídico podemos entender aquí un interés o estado de cosas que, conforme a las normas de un sistema jurídico, es merecedor de esa protección reforzada mediante coacción que brinda el Derecho (pp. 125-132).

Desde esta arista, el agente del Estado debe tener primero una atribución de función pública, esto es, que se conozca su mala intención (conocimiento) en reproducir esa notifica falsa y con ella cause un daño (voluntad) que sea doloso o culposo, y además comprobable, es decir, imputado subjetivamente y objetivamente, esto significa que exista una prohibición de regreso, un riesgo jurídicamente relevante que se haya concretizado (nexo causal), por medio de una conducta que no esté protegida por la norma (discurso), y que una vez trinado, 
comentado o publicado el comentario x, y o z en la red social haya contado con una divulgación masiva con rasgos de causar lesión o perjuicios a terceros (material).

\section{Falla del servicio a causa de una noticia falsa o malintencionada publicada en las redes sociales}

El marco de la responsabilidad estatal ha evolucionado con el tiempo desde la teoría de la responsabilidad indirecta, pasando por la responsabilidad directa, la teoría por la culpa, falta o falla en el servicio, hasta llegar a la culpa por el daño antijurídico, que le ha permitido a la sociedad ir adecuando la responsabilidad de las actuaciones del Estado a las nuevas realidades y circunstancias, sin dejar de lado los planteamientos clásicos, que lo dotan de un marco jurídico sólido. En estos nuevos tiempos el alcance de la obligación debe extenderse por lógica a los medios electrónicos en los que el Estado ha comenzado a actuar y a relacionarse con los ciudadanos, bajo el mandato de ley, que así lo ordena (Becerra, J. et al., 2015).

De este modo, así como la licitación pública es la regla general en la modalidad de selección en la contratación estatal, la falla del servicio es el común en la responsabilidad extracontractual del Estado ${ }^{15}$, y esto obliga a que deba ser probado ese acto ilegal, hecho, omisión, acción, operación, etcétera Es posible, entonces que exista un daño antijurídico o incumplimiento de las obligaciones, por ejemplo, derivado de un pánico económico, presentado cuando una autoridad x, y o z, induce en error mediante comunicación, acto, acción, operación, norma blanda, alocución, promulgado en Twitter, YouTube, Facebook, etcétera, a ciertos sectores en un tema de mercados, generando grandes pérdidas a personas.

15 "La falla del servicio ha sido en nuestro derecho, y continúa siendo, el título jurídico de imputación por excelencia para desencadenar la obligación indemnizatoria del Estado". Ver al respecto la sentencia del 7 de marzo de dos mil doce, rad. 20042, M. P. Andrade Rincón. 
Asimismo, podría presentarse que un servidor público, cumpliendo una función, pública suministre cierta información confidencial de la cual tiene conocimiento en investigaciones de inteligencia, violando la reserva del proceso y alterando el orden público y la seguridad nacional ${ }^{16}$, de la cual puede ocasionarse un daño inmaterial a un derecho constitucionalmente protegido, tal cual como lo es la honra o el buen nombre.

Actualmente, no tenemos precedentes locales enmarcados frente a esos hechos, esto es, relacionados con la responsabilidad estatal derivada por contenido de redes sociales en materia contractual o extracontractual, pero en revisión de la jurisprudencia contenciosa administrativa pudimos encontrar algunas providencias que nos pueden servir para nuestro propósito.

Frente a todo esto hemos dicho que debería darse un daño (o un incumplimiento de las obligaciones), un dolo o culpa grave del agente servidor público (o también del contratista ${ }^{17}$ ) que haya actuado no conforme con derecho en consonancia con un nexo causal, y en relación de las actividades con la entidad o bajo el manto del canal institucional, entendido como criterio material, en sentido general (en ejercicio de función pública), es decir, no sólo basta que sean opiniones personales en armonía con la descripción de su cuenta, sino también que su contenido esté inmerso en una relación especial de sujeción.

Desde este enfoque, un ministro de Hacienda o cualquiera otra autoridad revestida de facultades para expedir actos, ordenar, ejecutar una operación administrativa, puede causar una manifestación de la voluntad por medio de red social, piénsese si el Presidente mediante un comentario expresa algo en específico sobre el mercado de valores, resultando

16 Consejo de Estado, sentencia del 25 de abril de 2017, Exp. 36934, M. P. Jaime Enrique Rodríguez.

17 Artículo 86 de la Ley 1474 de 2011, "las entidades sometidas al Estatuto General de Contratación de la Administración Pública podrán declarar el incumplimiento, cuantificando los perjuicios del mismo, imponer las multas y sanciones pactadas en el contrato, y hacer efectiva la cláusula pena”. 
ulteriormente falso, causando repercusiones económicas a empresas, esto es, en ejercicio de sus funciones, ya sea como servidor público ${ }^{18} \mathrm{O}$ como particular, en vinculación o relación con estas facultades, podría causarse entonces en últimas una reparación directa o indemnización por incumplimiento, dependiendo la particularidades del caso.

De allí que pueda provenir una responsabilidad fiscal, penal o disciplinaria y también administrativa (o viceversa), siempre que haya relación o nexo con el Estado ${ }^{19}$; si no fuera así se tomaría como perjuicio civil en sentido iusprivatista ${ }^{20}$.

$18 \mathrm{Al}$ respecto, tenemos el caso de la sentencia del 6 de septiembre de 2017, Exp. 31534, M. P. Díaz del Castillo, “aquí la Procuraduría General de la Nación emitió un comunicado que difundió en su boletín, en el que de manera asertiva pone en evidencia una defraudación contra el erario público y el patrimonio de algunos docentes, que vincula a la actora. Señaló la publicación a la demandante por la expedición de certificaciones falsas, en su condición de pagadora del Colegio Externado Nacional Camilo Torres y se la relaciona con la compulsa de copias para que, tanto la Fiscalía como la Procuraduría Delegada para la Vigilancia Administrativa, adelantaran las investigaciones pertinentes. A lo que se suma la amplia difusión de la noticia en la prensa hablada y escrita, entre el 15 y el 16 de febrero de 1994, esto es, una vez los medios conocieron el Boletín fechado el día 14 anterior. Refiere que la afectación de su honra y buen nombre, además de un profundo dolor y sufrimiento, le generó un estado de depresión que no tendría que soportar, si se considera que se limitó a certificar como correspondía, acorde con las hojas de vida de los docentes; al punto que ninguna investigación se adelantó en su contra, sin perjuicio de que así lo difundió la demandada. Siendo así, la actora aboga por que se declare la responsabilidad personal y conexa del Procurador General, del Procurador Delegado para la Vigilancia Administrativa y de la Abogada Comisionada que conoció del asunto, dado que el comunicado y su difusión les competían en razón de sus funciones y jerarquía vulneración de derechos fundamentales a la honra, buen nombre y debido proceso". Véase también sentencia del 25 de mayo de 2016, rad. 35323, M. P. Rojas Betancourth, sobre: "Difusión de información errónea sobre supuestos colaboradores o integrantes de grupos guerrilleros".

19 Tenemos el caso de un tweet del expresidente Uribe, en el que le impusieron una medida privativa de la libertad. Luego, precluyeron la investigación, pero demandó por error judicial.

20 Ver al respecto, "Am i Facebook?: Sobre la responsabilidad civil de las redes sociales on-line por la lesión de los derechos de la personalidad, en particular por usos no consentidos de la imagen de un sujeto" de Ana Soler Presas, 2011, "Responsabilidad civil derivada de la vulneración de los derechos de la personalidad en la red de Lorena Parra Membrilla, 2017 o "La responsabilidad de las redes sociales: el caso de Ashley Madison” de Alejandro Platero Alcon, 2017. 
El meollo de esto, en todo caso, sería la cuantificación de ese daño con relación a los perjuicios indemnizables de la actividad extracontractual o incumplimiento contractual. Se podría exigir, además, ciertos reproches conforme a una posible desviación del poder del servidor público, lo cual daría inicio de una vez a que se incoe el medio de control de nulidad y restablecimiento del derecho o la reparación directa por ese trino, alocución o comentario publicado en la red social, convertido ahora en norma blanda, acto administrativo verbal, escrito o simbólico bajo el criterio material.

Lo que sí debemos tener claro es que el daño ocasionado, ya sea material (daño emergente o lucro cesante), pero, sobre todo, el inmaterial (intimidad, buen nombre), podría ubicarnos en la afectación de derechos constitucional y convencionalmente protegidos, como vulneración de garantías fundamentales individuales ${ }^{21}$, por lo que la transgresión a la honra es la lesión misma, esto es, contando con el análisis de las características ya mencionadas, que son: i) material, ii) cognoscitivo, y iii) volitivo, siendo visible siempre que va a ser demostrado no sólo ese daño, sino también la mala intención, es decir, el dolo, o en este caso de la responsabilidad estatal, la culpa grave.

La jurisprudencia más reciente que hemos revisado del Consejo de Estado sobre estos hechos, acciones, etcétera, abarcan el tema de la difusión de los medios de comunicación o de información falsa (mas no de redes sociales) con relación a la responsabilidad administrativa incluida en la sentencia del 12 de diciembre de 2019, Exp. 50075, M. P. Velásquez Rico ${ }^{22}$, en el que se consideró que:

21 Ver al respecto, la sentencia SC-10297-2014 de 05-08-2014 de la Corte Suprema de Justicia (Sala Civil), M. P. Salazar Ramírez.

22 Los hechos fueron que "la señora x se desempeñó como secretaria de Educación de Cundinamarca entre 2001 y 2003. En 2004 el gobernador de Cundinamarca y la entonces secretaria de Educación de Cundinamarca divulgaron, por medio del diario El Tiempo, que, en esa dependencia, durante el período de gestión de la actora, se pagaron salarios a "maestros muertos", entre otras anomalías, lo que provocó que se iniciaran procesos de responsabilidad fiscal en su contra. Finalmente, los procesos se archivaron en su favor debido a que las irregulari- 
Una vulneración del derecho a la honra, al buen nombre y a su imagen debe ser reparado, al habérsele imputado la comisión de una conducta punible sin que existiera prueba de ello. Además, señaló que el a quo cometió una falta absoluta de valoración del material probatorio (Consejo de Estado, 2019).

$\mathrm{Al}$ respecto, ha dicho la sentencia de la Corte Constitucional T-260 de 2010, y la providencia, también del Consejo de Estado del 24 de abril de 2017, Exp. 36934, M. P. Rodríguez Navas, expresó:

Con fundamento en lo anterior, se vulneraría el derecho al buen nombre o a la honra, cuando, sin fundamento alguno, se propagan entre el público -bien en forma directa y personal, ya a través de los medios de comunicación de masas- informaciones falsas o erróneas o especies que distorsionan el concepto público que se tiene del individuo y que, por lo tanto, tienden a socavar el prestigio y la confianza de los que disfruta en el entorno social en cuyo medio actúa, o cuando en cualquier forma se manipula la opinión general para desdibujar su imagen (Corte Constitucional, sentencia T-260 de 2020).

Aquí estamos frente a la acción de un agente del Estado (al emitir una opinión) con evidentes connotaciones sociales (que también pueden ser por la omisión difícilmente comprobable). Imagínense que en época del coronavirus un funcionario x profiere un "fake new" por trino o comentario en cualquier red social sin tener la base científica para ello, obteniendo como resultado, una asonada ${ }^{23}$, rebelión ${ }^{24}$ o se-

dades no existieron"; también revisar, referente a la responsabilidad del Estado por señalamientos públicos o sindicación de una persona a través de medios de comunicación, sentencia de 24 de abril de 2017, Exp. 23001-23-31-000-200500376-01(36934), M. P. Rodríguez Navas.

23 "Los que en forma tumultuaria exigieran violentamente de la autoridad la ejecución u omisión de algún acto propio de sus funciones, incurrirán en prisión de uno a dos años".

24 "Los que mediante el empleo de las armas pretendan derrocar al Gobierno Nacional, o suprimir o modificar el régimen constitucional o legal vigente, incurrirán en prisión de seis a nueve años y multa de cien a doscientos salarios mínimos legales mensuales vigentes”. 
dición ${ }^{25}$, esto por el temor o pánico de los ciudadanos en una desmejora en la salud pública, ocasionándose así graves daños.

Digamos que, del ejemplo anterior, se podría desprender perjuicios cuantiosos, entre ellos, a favor de ciertos establecimientos de comercio, personas, etcétera; indistintamente de la responsabilidad disciplinaria o penal que pueda atribuirse al sujeto agente. Ahora, desde el campo administrativo, ese daño ya sea material o inmaterial (indemnizable incluso por incumplimiento contractual) ocasionado en la esfera de los derechos fundamentales ${ }^{26}$ debe ser reparado por esa falla del servicio, pero que en últimas la tendrán que pagar los mismos ciudadanos, a diferencia de la civil.

Poniendo otro caso, pero real, que se presentó en el 2018, cuando se generó pánico económico ${ }^{27}$, causado por tweet, en el que se incitó a los ciudadanos a retirar su dinero porque al parecer serían embargadas sus cuentas por Estados Unidos si no la sacaban a tiempo, la Superfinanciera ${ }^{28}$ decidió interponer una denuncia por este delito.

25 "Los que mediante el empleo de las armas pretendan impedir transitoriamente el libre funcionamiento del régimen constitucional o legal vigentes, incurrirán en prisión de dos a ocho años y multa de cincuenta a cien salarios mínimos legales mensuales vigentes".

26 De Cupis, Adriano (1975), en "Daño: Teoría general de la responsabilidad civil”, en el que indica que "el derecho tutela, el daño vulnera”, p. 109.

27 Artículo 302 de la Ley 599 de 2000 dice: "El que divulgue al público o reproduzca en un medio o en un sistema de comunicación público información falsa o inexacta que pueda afectar la confianza de los clientes, usuarios, inversionistas o accionistas de una institución vigilada o controlada por la Superintendencia Bancaria o por la Superintendencia de Valores o en un Fondo de Valores, o cualquier otro esquema de inversión colectiva legalmente constituido incurrirá, por ese solo hecho, en prisión de treinta y dos a ciento cuarenta y cuatro meses, y multa de sesenta y seis punto sesenta y seis (66.66) a setecientos cincuenta salarios mínimos legales mensuales vigentes. En las mismas penas incurrirá el que utilice iguales medios con el fin de provocar o estimular el retiro del país de capitales nacionales o extranjeros o la desvinculación colectiva de personal que labore en empresa industrial, agropecuaria o de servicios. La pena se aumentará hasta en la mitad, si como consecuencia de las conductas anteriores se produjere alguno de los resultados previstos".

28 Ver "Superintendencia Financiera denunció publicaciones en Twitter por pánico económico”, 2018. 
Desde ese enfoque podríamos decir que pudo ocasionarse mal intención por noticia falsa divulgada, ahora, en caso tal que se hubiese demostrado que ese comentario en red social ocasiona un daño debería ser reparado a terceros.

Desde otro plano, ¿qué pasa si un funcionario de cualquier categoría realiza comentarios sobre política que lleven a insistir en la votación de algún candidato, o que un comentario trate de incidir en una decisión de otro, o peor, que mediante manifestaciones se vulnere la reserva de un proceso sancionatorio? Todo ello llevaría presuntamente a una responsabilidad que puede ser atribuible al Estado, ya sea contractual o extracontractualmente.

\section{Conclusión}

Se pudo plantear un abrebocas en este breve ensayo de lo que podría ser una responsabilidad estatal por el uso de las redes sociales por sus agentes, ya sea desde el plano contractual o extracontractual. Tuvimos algunas respuestas, pero muchas más preguntas. Decía Aristóteles: "la duda es el principio de la sabiduría", y con más razón en ese tema, tal cual como lo es la libertad de expresión, que apenas comienza a forjarse en el país desde el año 2016 y con cierto desarrollo a partir del $2019^{29}$, aun así, podremos concluir ciertas cosas.

En este punto, la responsabilidad del Estado se configuraría por el daño y por una imputación que se da, ya sea contractual o extracontractualmente, cuando exista un perjuicio o lesión causado por esa "falla del servicio" o "incumplimiento de las obligaciones", el cual puede ser ocasionado cuando se haya presentado un uso de los poderes exorbitantes, ya sea obligando al contratista a ejercer cierta conducta conforme a una publicación o comentario en una red social; o que por medio de un acto, hecho, actividad u operación, el agente del Estado divulgue o comparta cierta información falsa o malintencionado de lo que pueda resultar perjuicios económicos, morales, etcétera

29 Ver al respecto la sentencia T-155 y la SU-420 de 2019 de la Corte Constitucional. 
Se debe analizar entonces frente a un reproche, quién emite el contenido, así como el contexto, la cultura (adecuación social), y la coyuntura; igualmente, hacia quien va dirigido, es decir, si es una empresa privada o una entidad estatal ${ }^{30}$; qué tanta difusión tuvo; si fue por cuenta oficial, si tenía investidura o no, si es el competente, si cumple con los criterios descritos en la jurisprudencia, si incurrió en daño con dolo o culpa grave como imputación subjetiva ${ }^{31}$, y ahora objetiva, todos ellos serán los elementos de juicio pertinentes para establecer si hubo responsabilidad estatal como consecuencia de un contenido fraudulento, manipulado, insultante, etcétera, en una red social.

30 Al respecto ver "La responsabilidad del Estado por la utilización de las tecnologías de información y comunicación (TIC)” de Becerra, Jairo, Lorenzo Cotino Hueso, Claudia Bibiana García Vargas, Marco Emilio Sánchez Acevedo, Jheison Torres Ávila, 2015.

31 "Es claro que la jurisprudencia del Consejo de Estado tiene establecido que cuando respecto de una persona se publica una información que posteriormente se demuestra falsa, ello comporta un claro menoscabo a los derechos a la honra y al buen nombre de la persona afectada, lo que a su vez constituye un daño inmaterial, reparable por la vía del contencioso de responsabilidad extracontractual de la administración, en la medida en que el daño sea imputable a esta última”, véase sentencia del 5 de abril de 2013 del Consejo de Estado, Exp. 27281, M. P. Rojas Betancourth. 


\section{Referencias}

Becerra, J., Cotino, L., García, C., Sánchez, M., Torres, J. (2015). La responsabilidad del Estado por la utilización de las tecnologías de la información y la comunicación, Universidad Católica de Colombia.

Di Lellis, D. S. (4 de mayo de 2020). Il virus delle fake news. https://rep.repubblica.it/pwa/commento/2020/05/04/news/il_virus_delle_fake_news-255653078/?refresh_ce

García, A. (2011). "Responsabilidad Jurídica”. En: Revista en Cultura de la Legalidad, 1, pp. 125-132. https://e-revistas.uc3m.es/index.php/EUNOM/article/ view/2163/1098.

Pantaleón, F. (1996). "La constitución, el honor y el espectro de la censura previa, Revista Derecho Privado y Constitución”, 10. https://dialnet.unirioja.es/ descarga/articulo/181950.pdf.

Roa, D., y Daza, M. (2017). Deber funcional y libertad de expresión en redes sociales: Un diálogo sobre la responsabilidad del servidor público. Bogotá: Editorial Ibáñez.

Sánchez, J. F. (2018). Redes sociales: Del daño virtual a la responsabilidad legal. Bogotá: Universidad Sergio Arboleda.

Tamayo, J. (2017). "Reflexiones sobre la ontología del daño y la relación entre daño y perjuicio”. En: Nueva reflexiones sobre el daño. Medellín: Editorial Legis. 